to achieve this synthesis in brilliant style. $\mathrm{He}$ is a researcher who is active in the study of many astrophysical features of black holes and his striking simulations of the optical appearance of black holes are presented here in greater detail than ever before (but still without the use of mathematics). His style is lively and engaging, enlivened by interconnections with a wider culture than the purely scientific, and the translators have done an excellent job in reproducing some of the linguistic elegance of the original French. The amount of information conveyed is impressive. The intended audience is readers with some understanding of physics who are seeking a coherent, accurate nonmathematical overview of black-hole physics and all the astrophysical situations that the discipline seems to explain. Also, any student embarking on a serious technical study of general relativity or astrophysics will find the book a first-rate overview of an important part of the story. The treatment is broad and balanced, and Luminet is enviably patient in his determination to explain as much as possible and to make black holes as simple as possible, but no simpler. This is an outstanding work of scientific exposition that can be recommended as a manifestation of the dictum that common sense often leads to surprises and the modest goal of science is simply to make such surprises just a little less frequent. $\square$

John D. Barrow is in the Astronomy Centre, University of Sussex, Brighton BN1 9QH, UK.

\section{Bench notes}

An unusual laboratory diary to regulate the life of the harassed biochemist is on offer in the form of The 1993 Axel Biochemical Year Planner. Instead of containing unit-conversion tables and information on women's shoe sizes, this A5 week-to-view diary is crammed with lists of biomedical conferences to be held during 1993, more than 400 international research institutions, some 100 pharmaceutical companies, and databanks of cell and animal collections (with telephone and fax numbers). At the back are compilations of roughly 250 common biochemica! abbreviations; data on molecular weights, isotopes, restriction enzymes, DNA and proteins, and antibiotics and galactosides; laboratory recipes; acid, base and buffer charts; and even a sort of "Freezer Stock Location" filofax. And sitting rather self-consciously among all this is a wine chart - a fitting seasonal entry for the nonspecialist. Published by Axel Press Ltd, Kennett House, 108/110 London Road, Oxford OX3 9AW, UK. Price £3.99 (perfect bound), $£ 6.99$ (spiral bound). R.C.

\section{Onco-promotion} John Cairns

Genes and the Biology of Cancer. By Harold Varmus and Robert A. Weinberg. Scientific American Library (W. H. Freeman): 1992. Pp. 224. \$32.95, £17.95.

TEN years ago, two papers appeared in Nature announcing that the tumorigenicity of a human cancer was due to a point mutation in an oncogene. Since then, information has poured forth about the sequence changes in cancer cells. The normal functions of the altered genes are now fairly well understood, and the particular sequence changes in the different types of cancer have been shown, in some cases at least, to match what is known about the particular mutagenicity of the causative agent. The story is a perfect example of how molecular biology has clarified biology and biochemistry. At last, cancer starts to be understandable.

Varmus and Weinberg give a clear and exciting account of these developments, in which they themselves played a major part. The very beginning of the story was somewhat before their time, and this is the only part of their account that I would question. They say: "By the late $1940 \mathrm{~s}$. . . the target of carcinogens was no longer elusive". In fact, the cancer establishment reacted extraordinarily slowly to the coming of molecular biology. E. Boyland, P. Brookes and P. Lawley were about the only people in cancer research in the 1940 s and ' $50 \mathrm{~s}$ who believed that chemical carcinogens interact with DNA. In 1952, Boyland was ridiculed in print by $\mathrm{E}$. and $\mathrm{J}$. Miller who felt sure that the target was protein. As late as 1963, H. Pitot and C. Heidelberger were arguing that carcinogens interact with the proteins that regulate gene expression. What settled the matter were the experiments of Brookes and Lawley in 1964 and the results of microbial mutagenicity assays using liver extracts to achieve metabolic activation - a test invented by $F$. Mukai, W. Troll and H. Malling in 1969 and then systematized by Bruce Ames. But these are minor details. The book is excellent, and I am sure it will be very useful to all those biologists who want the latest news about the oncogenes.

I do not think the book will be of much help to the general public, but it will make a handsome addition to the art books on coffee tables. And that may have been exactly what the publishers had in mind when they created the Scientific American Library Series. For example, the first set of pictures in Genes and the Biology of Cancer shows a fertilized egg, a blastula, a mammalian embryo and the final product - a young girl about to plunge her chopsticks into what appears to be a bowl of bouillabaisse. Those four pictures (in exquisite colour) take up as much space as the subsequent brief introduction to DNA, RNA, protein and the genetic code. No reader who needs to be told about cells will understand such a compressed summary.

Scientists have a difficult time when they try to explain their work to the lay public. The safest bet is to go for a strictly historical approach as used by D. Dressler and $\mathrm{H}$. Potter in the companion volume called Discovering Enzymes. But it is not easy. Begin right at the beginning, and you will feel that you are wasting too much time on the preliminaries; begin in medias res, and you know you will be incomprehensible. So you aim for something in between and rely on your nonscientific friends and your copy editor to tell you where you are taking too much for granted. That, I suspect, was the stage missed out in Genes and the Biology of Cancer. It is, for example, fine to have a picture illustrating the transformation of pneumococci by DNA, but you must tell the reader that it shows the two types of bacterial colonies, not the bacteria themselves; without this explanation, the photograph is a waste of space because it will be understood only by those who have already seen it. The same can be said for many of the diagrams; it is common practice to show DNA sequences as a series of boxes (representing the exons, introns, long terminal repeats, insertion sequences, promoters, operators and so on), but this kind of abstraction should be preceded by a clear description of the relationship between sequence and function.

If the target of the book is the general public, I think that much more space should have been devoted to the origins and ideas of molecular biology; after all, these are what underlie all the things now known about "genes and the biology of cancer". If the target is primarily undergraduates and senior highschool students (all of whom already know about cells, if not about DNA), they should not have to pay for the many unnecessary colour pictures, put in simply to guide the book onto a few coffee tables.

John Cairns is at the Clinical Trials Service Unit, Harkness Building, Radcliffe Infirmary, Oxford OX2 6HE, UK.

Scientific American Books (W. H. Freeman) recently published a revised second edition of the acclaimed introductory text Recombinant DNA by J. D. Watson, M. Gilman, J. A. Witkowski and M. J. Zoller. $£ 33.95$ (hbk), £21.95 (pbk).

NATURE · VOL 360 - 17 DECEMBER 1992 